\title{
Investigating Differential Learning Outcomes of Students in Physics Using Animation and Textual Information Teaching Strategies in Ondo State Secondary School
}

\author{
Blessing Eguabor ${ }^{1 *}$, Ademola Moruf Adeleke
}

1 Obafemi Awolowo University Ife, Osun State

*Corresponding Author: beguabor@yahoo.com

Citation: Eguabor, B. and Adeleke, A.M. (2017). Investigating Differential Learning Outcomes of Students in Physics Using Animation and Textual Information Teaching Strategies in Ondo State Secondary School. European Journal of Sustainable Development Research, 1(2), 10.

doi: $10.20897 /$ ejosdr.201710

Published: June 30, 2017

\section{ABSTRACT}

\section{Background}

The study investigated the main effects of animation information and textual information on students' performance and improving students' attitude towards physics.

\section{Material and methods}

The study adopted the pre-test post-test control group design. The population was made up of SSS 2 students in Ondo State. Three Local Government Areas were randomly selected from the 18 Local Government Areas of Ondo State. Simple random technique was used to select three schools in the selected Local Government Areas. The schools were randomly assigned to two experimental groups namely animation and, textual information strategy and one control group. Two instruments were used for the study.

\section{Results}

One-way Analysis of Variance (ANOVA), Scheffe Post-Hoc pair-wise comparison Analysis, and two-way Analysis of Variance was used. The results showed that there was a significant main effect of animation and textual strategies on students performance in physics. The results also showed that there was a significant difference in the post test attitudinal score of students' exposed to the strategies with the effectiveness in the order of animation, textual, and conventional strategies

\section{Conclusions}

The study concluded that computer- based instruction such as animation and textual strategies could enhance learning outcomes in Physics in senior secondary school irrespective of students' sex.

Keywords: bibliotherapy, literature and picture books, mathematics confidence, STEM

\section{INTRODUCTION}

Physics is an indispensable tool for the advancement of technology and economy in order to meet the challenges of $21^{\text {st }}$ century. Studying Physics at school is an excellent preparation for a range of challenging and rewarding degree courses and careers both inside and out of the sciences (Wendy, 2011).

However, despite the importance of physics, research over the years still shows a number of problems encountered in learning of Physics. Lack of students `interest in Physics, gender imbalance, the method of teaching and interest in the contents of Physics; have been identified as part of factors that affect students' learning in 
Physics (Simon and Stokking, 2000). In addition, research has provided information that attitude towards science changes with exposure to Physics, but the direction of change may be related to the quality of that exposure, the learning environment and teaching method. Craker (2006) stated that if students have negative attitudes towards science, they also do not like physics courses and physics teachers.

Based on this premise, numerous studies have been conducted to determine the factors that affect the students' attitude to science and their performance in it. A summary of such studies maintain that factors such as teaching -learning approaches, type of science courses taken, methods of studying, intelligence, gender, motivation, science teachers and their attitude, self-adequacy, cognitive style of students, career interest, socio-economic levels, influence of parents, among others do affect students' performance and attitude to science (Dieck, 1997; Halladyna and Shanghnessy, 1982; Mattern and Schau, 2002; Normah and Salleh, 2006; Rivard and Straw, 2000).

In view of the above, it is very clear that efforts had been made by the people of concerned minds in the past and also in present time to improve the performance of students in physics, and in spite of these, learning outcome in Physics is still on the low trend. One can infer from the foregoing that, in order to improve Physics learning outcomes there is a need to explore strategies that can captivate the interest of the students towards learning physics better and improve their performances.

No matter how highly organized lecture method might be, the use of computer-based multimedia instruction in most African countries tends to arouse the interest of students in Physics (and indeed in most school subjects) more than teacher-based instruction. Ijhedo, (1995) explained that the use of audio-visual aids in sciences has been found to be an effective way of communicating ideas and concepts to students.

In an attempt to address these issues, many researchers have focused on various teaching methods and strategies in physics. According to Obasa (2000) in Adeyemo (2012), student's academic performance is affected by teachers in terms of the mastery of course content and teaching methodology, image and commitment/dedication to duty. A good number of our teachers are highly deficient in the subjects, as they teach what they are not supposed to teach or skip certain areas of the syllabus at they find difficult. Adodo (2005) was in support that academic achievement may be dependent upon positive attitude from the teachers and the students in the teaching/learning processes. To this end, Oladejo et al., (2011) explained that poor academic achievement in Physics could be attributed to many factors among which teacher's strategy itself was considered as an important factor.

To avert this, teaching strategy should be structured in a way that it can captivate the interest of the student. Today students do not do well in Physics because it does not capture their attention, but cartoons and animations have been found to arrest the attention of the students. Gao and Zhag (2013) pinpointed the various advantages of multimedia teaching technology over traditional teaching tools, these include to; enhance the effect of teaching information transfer, give full play to the advantages of visual media information dissemination, make the abstract knowledge more close to reality, increase the teaching information and improve the teaching efficiency, stimulate the students' learning interest and reduce the learning difficulty. The authors further stressed that the multimedia teaching can display the dynamic image and colorful graphics, transfer a large number of teaching information in a short time by combining the auditory and visual channels.

Adegoke 2010 further stressed that integrating animation and textual in a computer-based environment may help to improve students' learning outcomes in physics. This result suggested that multimedia instruction is a way of reducing students' low level of interest and cognitive achievement in physics. More importantly, students' who learn physics in computer -based multimedia environment tend to achieve better learning outcomes in physics than their colleagues who learn physics under teacher- based environment. Thus, learning outcomes in physics can be enhanced by the use of multimedia packages. There is the need therefore to explore the possibility of improving learning outcomes in Physics by combining the elements of multimedia animation with instructional strategies.

\section{OBJECTIVES OF THE STUDY}

It is very important for a science teacher to have full knowledge of the subject matter and be creative in developing multimedia packages that are best for teaching and learning process. The objective of this study was to improve the learning outcomes in Physics by enhancing the teaching of physics in secondary school through the use of multimedia instructional packages. This study is therefore designed to:

i. determine the main effects of animation information and textual Information on students' performance in Physics; and

ii. examine the effectiveness of animation information and textual information in improving students' attitude towards Physics. 


\section{RESEARCH HYPOTHESES}

Two research hypotheses were raised for the study:

i. There is no significant main effect of animation and textual information strategies on students' performance in Physics.

ii. There is no significant difference in the effectiveness (post-test attitudinal scores) of animation, textual information and conventional strategies in improving students' attitudes to Physics.

\section{PROCEDURE}

The study adopted the pre-test post-test control group design. The population made up of Senior Secondary School class two (SSS-II) science students of Physics in Ondo State. Three Local Government Areas were randomly selected from the 18 Local Government Area of Ondo State. The simple random technique was used to select three schools in the selected Local Government Areas. All Physics students in intact classes in the selected schools were involved in the study. Three teachers were trained as research assistants in carrying out the study. The schools were randomly assigned to two experimental groups and one control group. Students in experimental group 1 were exposed to the use of Animation only, those in experimental group II was exposed to the use of Textual Information only while students in the control group were exposed to conventional teaching method. The instrument for the study includes Physics Achievement Test (PAT) and Attitude in Physics Questionnaire (APQ) which was used to gather pre-test and post-test data.

The research involved three main stages, namely the pre-treatment stage, the treatment stage and post-treatment stage which lasted for six weeks. At the pre-treatment stage, the researcher visited the selected schools for notification and solicited for assistance from school management. This was followed by a discussion with the physics teachers in each school with the view of briefing them the purpose and objectives of the study. The arrangement was made by the researcher with the selected teachers on the convenient time for proper orientation for the study. The two selected teachers for experimental group were trained as research assistants on how to use animation information and textual information while the third teacher did not undergo special training for the control group since the teacher was already familiar with the conventional method of teaching.

In addition, on the first week of administering the treatment, a pre-test was carried out on the first day on the participating students. This was followed by grouping the students into animation and textual information. From the second week to the fifth week of the study, teaching took place and the students in each group were taught by the research assistants using the packages designed by the researcher.

In the animation information group, trained teacher set up equipment-laptop on which presentation has been saved and the digital projector with a generator as a source of power. The animated instructional package was then projected on the white screen; the teacher instructed the 52 students in the group to pay attention and jot down what they have learned in their physics notebook while viewing the animation.

In the textual information group, which was made up of 44 students, were instructed by the teacher to also pay attention and jot down what they learnt from viewing the textual instructional package that was projected on the white screen. 31 students in the control group were not be given any specific instruction. Normal conventional classroom interactions were condoned.

In the last week of the study, the PAT was administered to the students as post-test so as to determine their level of achievement. At this stage also, APQ was administered to the students' in order to determine students' attitude towards physics. The two instruments were administered to both the experimental and control groups at the end of the treatment. The scores obtained constituted the post-test performance and attitudinal scores for the students.

\section{RESULTS}

To find out the homogeneity, the pre-test scores of Physics Achievement Test (PAT) in the three groups were analyzed using one way Analysis of Variance (ANOVA) at 0.05 level of significance. The result is presented in Table 1.

Table 1, shows that there was no significant difference in the pre-test performance scores of students' in the three groups $(\mathrm{F}=0.486, \mathrm{P}=0.937)$ at 0.05 level of significance. This is an indication that at the beginning of the experiment, students in the groups were at the same level of performance.

The testing of the two hypotheses for this study was undertaken to ascertain whether they would be rejected or not. 
Table 1. One way ANOVA Showing the Academic Performance of Students of the three Group in Pre-test.

\begin{tabular}{|l|r|r|r|r|r|}
\hline & Sum of Squares & Df & Mean Square & F & Sig. \\
\hline Between Groups & 4.551 & 14 & .325 & 0.486 & \\
Within Groups & 74.977 & 112 & .669 & & \\
Total & 79.528 & 126 & & & \\
\hline
\end{tabular}

Table 2. Descriptive Statistic in Students' Pre and Post Treatment Physics Performance Scores.

\begin{tabular}{|c|c|c|c|c|c|c|c|c|}
\hline & \multirow[b]{2}{*}{$\mathrm{N}$} & \multirow[b]{2}{*}{ Mean } & \multirow[b]{2}{*}{$\begin{array}{l}\text { Std. } \\
\text { Deviation }\end{array}$} & \multirow[b]{2}{*}{ Std. Error } & \multicolumn{2}{|c|}{ 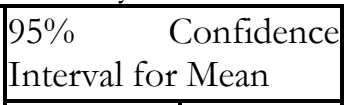 } & \multirow[b]{2}{*}{ Minimum } & \multirow[b]{2}{*}{ Maximum } \\
\hline & & & & & $\begin{array}{l}\text { Lower } \\
\text { Bound }\end{array}$ & $\begin{array}{l}\text { Upper } \\
\text { Bound }\end{array}$ & & \\
\hline pre animation & 52 & 8.8654 & 2.89712 & .40176 & 8.0588 & 9.6719 & 3.00 & 17.00 \\
\hline post animation & 52 & 17.2500 & 2.89608 & .40161 & 16.4437 & 18.0563 & 8.00 & 23.00 \\
\hline pre textual & 44 & 7.2955 & 2.66397 & .40161 & 6.4855 & 8.1054 & 2.00 & 15.00 \\
\hline post textual & 44 & 15.3864 & 2.91919 & .44008 & 14.4988 & 16.2739 & 10.00 & 21.00 \\
\hline pre control & 31 & 8.0968 & 2.85604 & .51296 & 7.0492 & 9.1444 & 3.00 & 13.00 \\
\hline post control & 31 & 9.6452 & 2.91603 & .52373 & 8.5756 & 10.7148 & 4.00 & 17.00 \\
\hline Total & 254 & 11.4409 & 4.87577 & .30593 & 10.8384 & 12.0434 & 2.00 & 23.00 \\
\hline
\end{tabular}

Table 3. Summary of One -Way ANOVA of performance students of exposed to animation, textual strategies and conventional teaching method.

\begin{tabular}{|l|l|l|l|l|l|}
\hline & Sum of Squares & Df & Mean Square & F & Sig. \\
\hline Between Groups & 3987.409 & 5 & 797.482 & 97.561 & .000 \\
Within Groups & 2027.205 & 248 & 8.174 & & \\
Total & 6014.614 & 253 & & & \\
\hline
\end{tabular}

Table 4. Scheffe's Pair wise Multiple Comparison Pre and Post Treatment Physics Performance Scores.

\begin{tabular}{|l|l|r|r|r|}
\hline$(\mathrm{I})$ strategies & $(\mathrm{J})$ strategies & Mean Difference (I-J) & Std. Error & Sig. \\
\hline pre-test animation & post-test animation & $-8.38462^{*}$ & .56874 & .000 \\
\hline pre-test textual & post-test textual & $-8.09091^{*}$ & .61829 & .000 \\
\hline Pre- test control & post test control & -1.54839 & .73661 & .730 \\
\hline
\end{tabular}

Hypothesis 1: There is no significant main effect of animation and textual information strategies on students' performance in Physics.

This hypothesis was raised to find out the effect of the strategies on students' performance. In testing this hypothesis, the score of the pre-test and post-test of students in the three groups were compared and subjected to descriptive and inferential statistical using one way Analysis of Variance (ANOVA) at 0.05 level of significance. The results are presented in Tables $2-4$.

Table 2 shows the mean pre-test performance score of the students in each of the learning strategy group as mean values are 8.8654, 7.2955 and 8.0968 respectively for animation, textual and control. While, the posttreatment Physics performance means score are 17.2500, 15.3864 and 9.6452 of the students in each of animation, textual and control modes of instruction respectively. This is an indication that students exposed to animation strategy performed best, followed by textual strategy while students' in control performed least.

The results in Table 3 show a significant difference between the pre and post scores in each strategy and among students' performance in the three strategies $(\mathrm{F}=97.561, \mathrm{P}=0.00)$. This result suggests an existence of a significant effect of each strategy on student performance in physics, as well as the difference in the effect across the strategies. In order to understand the direction the difference Scheffe's Post Hoc analysis was carried out and the result is as presented in Table 4.

The results in Table 4 show the different direction of differences between pre and post test scores in all the strategies. The results clearly show that animation and textual had an effect on students' performance in physics while control did not have an effect on students' performance at 0.05 level of significant. 
Table 5. Descriptive Statistic of Pre and Post Treatment of Physics students' Attitudinal Scores.

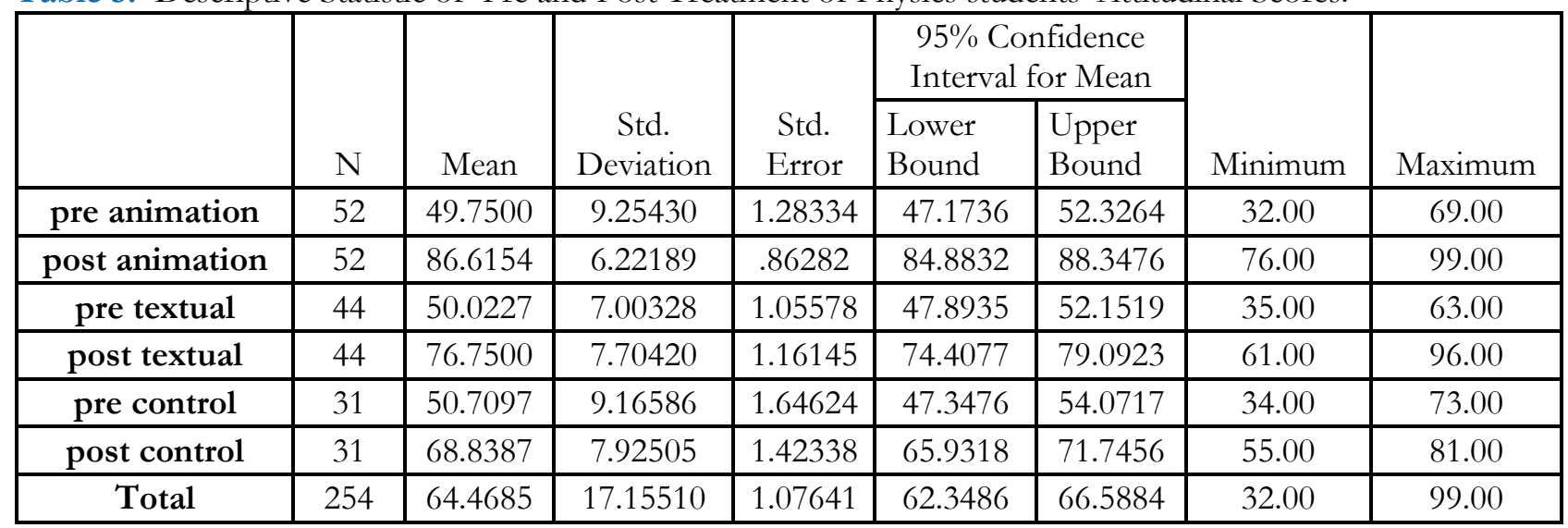

Table 6. One -Way ANOVA showing the Attitudes of students exposed to animation, textual strategies and conventional teaching method.

\begin{tabular}{|l|l|l|l|l|l|}
\hline & Sum of Squares & Df & Mean Square & F & Sig. \\
\hline Between Groups & 59049.382 & 5 & 11809.876 & 190.088 & 0.000 \\
Within Groups & 15407.866 & 248 & 62.128 & & \\
Total & 74457.248 & 253 & & & \\
\hline
\end{tabular}

Table 7. Scheffe's Pair wise Multiple Comparison Pre and Post Treatment Physics students' Attitudinal Scores.

\begin{tabular}{|l|l|r|r|r|}
\hline (I) strategies & (J) strategies & Mean Difference (I-J) & Std. Error & \multicolumn{1}{c|}{ Sig. } \\
\hline pre-test animation & post-test animation & $-36.86536 *$ & 1.66662 & .000 \\
\hline pre-test textual & post-test textual & $-26.72727 *$ & .1 .81181 & .000 \\
\hline Pre- test control & post test control & $-18.12903 *$ & 2.15853 & .000 \\
\hline
\end{tabular}

Hypothesis 2: There is no significant difference in the effectiveness (post-test attitudinal scores) of animation, textual information and conventional strategies in improving students' attitudes to Physics.

This hypothesis was raised to find out the effect of the strategies on students' attitude towards physics. In testing this hypothesis, the attitudinal score of the pre-test and post-test of students in the three groups were compared and subjected to descriptive and inferential statistical using one-way Analysis of Variance (ANOVA) at 0.05 level of significance. The results are presented in Table 5, Table 6 and Table 7.

Table 5 shows the mean pre-test attitudinal score of the students in each of the learning strategy group as mean values are 49.7500, 50.0227 and 50.7097 respectively for animation, textual, and control. While, the post-treatment Physics attitudinal means score are 86.6154, 76.7500 and 68.8387of the students in each of animation, textual and control modes of instruction respectively. This is an indication that students exposed to animation strategy performed best, followed by textual strategy while students' in control performed least.

The results presented in Table 6 show that students' attitudes to physics differed when compared before and after post treatment in each group and also differed from one group to the other $(\mathrm{F}=190.088, \mathrm{P}=0.00)$. The results indicated effect of the strategies on students' attitude to physics as well as some measure of the effectiveness of the strategies in improving the attitude. In order to better understand the direction of the difference, Scheffe's Post-Hoc of multiple comparisons among the group was carried out. The result is presented in Table 7.

The results in Table 7 show clearly that each strategy has an effect on students' attitudes to physics with the mean post-test score of each strategy being higher than the pre-test mean score all at $\mathrm{P}=0.00$. Specifically, the mean difference between post-test and pre-test score of animation (36.86) was also found to be significantly higher than that of textual (26.73), and that that of control (18.13) at $\mathrm{P}=0.00$. Equally the difference in post-test mean score of students' attitude to physics in animation group and textual (9.86) was lower than the difference in animation and control groups (17.78). All of these point to the difference in the effectiveness of the strategies in improving students' attitude to physics with animation being the most effective followed by textual and then conventional strategies. 


\section{DISCUSSION}

\section{Animation Information and textual information strategies Improves Learning Outcomes in Physics}

The findings of this study revealed that there is no significant difference in the performance of students' exposed to animation, textual and conventional method of instruction in physics before the treatment, this implies that the three groups are the same at the beginning of the study. Summary of the analysis of data collected on hypothesis one, which states that there is no significant difference between the pre and post test performance scores of students exposed to animation and textual information strategies in physics showed that animation and textual strategies have a significant effect on students ` performance by improving it. In other words, students that were exposed to the treatment by their teachers performed better than the students in the control group. The result is in agreement with the finding of Anddy et al., (2002), who found that multimedia learning system, which is an interactive educational tool, enhances students understanding. This also corroborates the findings of Adegoke (2010) who found out that animation, textual information in a computer-based environment may help to improve students' learning outcomes in physics. From the result, which indicated that students exposed to animation strategy performed best, followed by textual strategy while students' in control performed least suggested that multimedia instruction is a way of reducing students' low level of cognitive achievement in physics.

Hypothesis two was raised to find out the effect of the strategies on students' attitude towards Physics. The results showed that there is a significant effect of the strategies on students' attitudinal scores in physics. The result is in agreement with Adefuye (2000) and Onuoh (1986) cited in Adeyemo (2011) that explained that the presence of various learning resources in schools, such as audiovisual aids, arouses students' interest towards learning. Also, this result agreed with Aina et al., (2013) who of the viewed that low student interest and lack of motivation among others factors causes low enrolment in science which results to poor performance in a science subject. In other words, the results of this study shown that learning outcomes can be enhanced by integrating instructional packages such as computer based package; animation information and textual information e.t.c in learning of physics in senior secondary school.

Learning of physics in the classroom that solely based on theoretical, influences the learning outcomes negatively. Thus physics teaching and learning processes should be structured in other to take care of students learning outcomes that can captivate and stimulate the interest of the students for better performances. In order to make physics learning and teaching process more captivating, the teacher should employ the use of instructional packages such as cartoon, computer-based materials and likes, the teacher should be creative and technological inclined. Such strategies will improve the student's attitude towards physics learning for better performances.

\section{CONCLUSION}

It was found that animation information and textual information had an effect on students' performance and improving students' attitude towards physics. The study concluded that computer- based instructional strategies such as animation and textual strategies could enhance learning outcomes in Physics in senior secondary school. Physics teachers should, therefore, be encouraged to adopt the use of computer-based instructional packages in teaching process to enhance students learning outcomes.

\section{RECOMMENDATIONS}

The following recommendations were made based on the findings from this study:

i. Physics teachers should be competent in the use of the computer so as to be able to develop educative instructional packages that can enhance learning outcomes.

ii. School authority should organize periodic seminars for both teachers and students, so as to train them on computer-based instructional packages that can improve learning and teaching process.

iii. Ministry of education should support school authority in organizing seminars based on computer instructional packages.

iv. The government should design and implement curriculum packages that will integrate the use of computer-based strategies for teaching and learning process.

\section{REFERENCES}

Adegoke B.A (2010). Integrating animations, narrative and textual information for improving physics learning. Electronics journal of Research in Educational Psychology. 8(22) 725-748. 
Adegoke, B.A. (2011). Effect of Multimedia Instruction on Senior Secondary School Students' Achievement in Physics. European Journal of Education Studies. 3(3), iuuuukiuk, 537-550.

Adeyemo A. S (2012). The relationship between effective classroom management and students' academic achievement: European journal of Educational studies. 4(3), 367-381

Adeyemo A. S. (2011). The effect of teachers perception and students' perception and students' perception of physics classroom learning Environment on their Academic Achievement in Senior secondary schools physics. International journal of Educational Research and Technology. 2(1), 72-81

Adodo, S.O. (2005).Effect of diagnostic remediation instructional strategies and students learning outcomes in junior secondary school integrated science. Unpublished PhD Thesis, University of Ado-Ekiti, Ekiti State.

Aina, J. K and Adedo G. A. (2013). Perceived Causes of Students' Low Enrolment in Science in Secondary Schools, Nigeria. International Journal of Secondary Education. 1(5), 18-22

Anddy, A; Kevin, L and Voon, C.K. (2002). Multimedia learning systems: a future interactive educational tool. The internet and higher Education. 6(3), 25-40

Craker, D.E. (2006). Attitude toward science of Students enrolled in introductory level science courses at UW-LA. Journal of Undergraduate Research.9, 1-6

Dieck, A.P. (1997) Aneffect of newsletter on children's interest in an altitude toward science. Master thesis, Arizonal State University.

Gao, Z. and Zhang, J. (2013). The Further Understanding in Multimedia Teaching of College Based on Education Dissemination. International Conference on Education Technology and Management Science. 1107-1110

Haladyna, T. And Shaughnessy, J. (1982) Attitudes towards science. A qualititative synthensis. Journal of Research in Science Teacbing 66(4): 547-563

Ijhedo, J. A. A (1995) Quasi- experiment Research on effect of synchronized instructional recourses in Automobile Education. A case study University of London.

Maltern, N. and Schau, C. (2002). Gender difference in attitude achievement relationship over time among while middle school school students. Journal of Research in Science Teaching 39(4), 324-340.

Normal, Y. and Salleh, I. (2006) Problem solving skills in probability among matriculation student paper presentented at National Educational Research Seminar xiii, 40-55

Oladejo, M. A; Olosunde, G.R; Ojebisi, A.O and Isola, M.O. (2011). Instructional materials and students' Academic Achievement in Physics; some policy implications. European Journal of Humanities and social Science. 2(1), $112-126$

Onocha, C. O. (1985). Pattern of relationships between home and school factors and pupils' learning outcomes in Bendel Primary Science Project. Unpublished PhD Thesis, University of Ibadan.

Rival. L.P and Straw, S.P. (2000).Attitude of students towards the study of Physics. American International Journal of contemporary Research. 2(12)

Simon and Stokking, (2000). Pupil interest in physics. A survey in Finland pg 74

Wendy, P. (2011). Physics and its advantage. IOP institute of physics. 